\title{
Day-to-day Variation of Salivary Cortisol and Dehydroepiandrosterone (DHEA) in Children from a Rural Dominican Community
}

\author{
Davide Ponzi • Michael P. Muehlenbein • \\ Andrea Sgoifo • David C. Geary • Mark V. Flinn
}

Received: 12 March 2014 / Accepted: 5 June 2014 /Published online: 19 June 2014

(C) Springer International Publishing 2014

\begin{abstract}
This study examines day-to-day patterns of salivary cortisol and dehydroepiandrosterone (DHEA) under baseline conditions and in response to mild stress among 59 children residing in a rural Caribbean village. Cortisol secretion showed the typical circadian variation with high levels in the morning. Children showed significant increases of cortisol before and during a videotaped interview when compared to routine days. DHEA levels were positively associated with cortisol levels; however, within-day secretion of salivary DHEA was more stable than cortisol and DHEA levels did not change significantly during the day. Average DHEA concentrations were positively associated with age but did not show the sharp increase that is usually observed at the onset of adrenarche. These results highlight both similarities and differences in the secretion of cortisol and DHEA during childhood among rural and industrialized human populations.
\end{abstract}

Keywords HPA C Cortisol DHEA - Dominica - Multilevels models · Psychosocial stress

D. Ponzi

Division of Biological Sciences, University of Missouri, Columbia, MS 65201, USA

M. P. Muehlenbein

Department of Anthropology, Indiana University, Bloomington, IN 47405, USA

A. Sgoifo

Department of Evolutionary and Functional Biology, University of Parma, 43100 Parma, Italy

D. C. Geary

Department of Psychological Sciences, University of Missouri, Columbia, MS 65201, USA

M. V. Flinn

Department of Anthropology, University of Missouri, Columbia, MS 65201, USA

D. Ponzi $(\bowtie)$

Institute for Mind and Biology, University of Chicago, Chicago, IL 60637, USA

e-mail: ponzdbiol@gmail.com 


\section{Introduction}

Cortisol and dehydroepiandrosterone (DHEA) are adrenal steroids that can be reliably measured in saliva where they are highly correlated with total hormone blood levels and with free hormone concentrations in plasma (Goodyer et al. 1996). Although cortisol's metabolic functions are well known, DHEA's physiological role remains unclear. DHEA is the most abundant circulating androgen in the human body. Despite its very low androgenic activity, DHEA can be converted to testosterone (T), dihydrotestosterone (DHT), and estrogen (Labrie 2004) in peripheral tissues. DHEA is also secreted by the gonads, and it is synthesized de-novo in the brain, where it can act as a neurosteroid (Conley and Bird 1997; Corpechot et al. 1981; Majewska 1995). Animal studies show that DHEA may have anti-glucocorticoid effects, such as decreasing the neurotoxic effects of high cortisolemia on the hippocampus (Karishma and Herbert 2002; Kimonides et al. 1999).

Much research on cortisol and DHEA in psychology and anthropology has focused on the effect of stress on these hormones. In response to an acute stressor, such as a socio-evaluative event, the hypothalamus secretes corticotropin-releasing hormone $(\mathrm{CRH}), \mathrm{CRH}$ then stimulates the production of adrenocorticotropin hormone (ACTH) from the anterior pituitary gland and $\mathrm{ACTH}$, in turn, stimulates the secretion of cortisol from the adrenal gland (McEwen and Gianaros 2010). If stress becomes chronic, the initial hyperactivity of the hypothalamic-pituitary-adrenal (HPA) axis is usually followed by hypoactivity and chronic hypocortisolism (Fries et al. 2005; Miller et al. 2007; Jankord and Herman 2008). Similar to cortisol, the secretion of DHEA depends on $\mathrm{ACTH}$, and DHEA is released during acute psychosocial stress along with cortisol (Izawa et al. 2008; Lennartsson et al., 2012; Marceau et al., 2014; Shirtcliff et al., 2007). However, the DHEA response to stress is not as well characterized as the cortisol response, and little is known about changes in DHEA in relation to chronic stress.

A pre-requisite for understanding the impact of acute and chronic stress on hormones such as cortisol and DHEA is knowing their diurnal patterns of fluctuations and their age-related changes early in life. In humans, cortisol secretion exhibits a circadian rhythm that relates closely to the time of waking (Edwards et al. 2003). Cortisol levels peak within one hour after waking and then steadily decrease until reaching their lowest concentration in the evening (Weitzman et al. 1971). This diurnal fluctuation in cortisol levels has been observed in infants as young as 3 months old (Price et al. 1983), and continues to occur through childhood (Gunnar and Quevedo 2007). Baseline cortisol levels are relatively stable, with slight increases during childhood and aging (Styne and Grumbach 2008). Diurnal fluctuations in cortisol levels are also stable over time, in the absence of stress or pathological conditions (Edwards et al. 2003; Hruschka et al. 2005), although hormonal fluctuations in relation to mood can occur (Adam 2006).

The body's secretion of DHEA generally follows the diurnal pattern of cortisol (Auchus and Rainey 2004; Ibanez et al. 2000; Rosenfeld et al. 1971), with morning's higher levels waning as the day progresses. However, DHEA does not appear to spike after awakening and is more stable than cortisol during the day (Hucklebridge et al. 2005; Granger et al. 1999; Labsy et al., 2013). DHEA begins to be secreted at high levels during mid-childhood, in conjunction with the occurrence of adrenarche (Auchus and Rainey 2004; Nguyen and Conley 2008) and the pattern of DHEA secretion over the life span is different from that of cortisol (Auchus and Rainey 2004; van Cauter 
et al. 1996). Given DHEA's antiglucocorticoid actions, some have speculated that the function of adrenarche is to protect the developing brain from high cortisol neurotoxicity resulting from an increased exposure to socially and physically stressful events (Campbell 2006; Flinn et al. 2011).

In addition to knowledge of diurnal fluctuations and developmental changes in hormone secretion, to fully understand hormonal responses to stress it is also important to take into account individual differences in hormone baseline levels. Before puberty, basal and reactive cortisol secretion does not show significant sex differences (Kajantie and Phillips 2006), while in adults either no sex differences or higher basal cortisol levels in men have been reported (Kudielka and Kirschbaum 2005). Sex differences in DHEA secretion begin at puberty and women appear to have higher levels of DHEA compared to men (Sulcova et al., 1997). Differences in basal levels of cortisol and DHEA have also been reported in relation to ethnicity. For example, higher levels of serum and urinary adrenal steroids have been reported in African-American and Caribbean-Hispanic girls relative to European American girls (Girgis et al. 2000; Havelock et al. 2004; Pratt et al. 1990), while flatter diurnal slopes of cortisol have been reported in African-American and Hispanic adolescents, regardless of sex (DeSantis et al. 2007). The reasons for these differences are not clear and may involve genetic, metabolic (Girgis et al. 2000) and social (DeSantis et al. 2007) factors.

Most data on diurnal fluctuations, developmental changes, and interindividual variation in baseline cortisol levels have come from western industrialized societies; very few cross sectional or longitudinal studies of salivary adrenal steroids (either under basal conditions or in response to stress) in children from developing countries have been conducted (Nyberg 2012; Flinn and England 2003; Flinn 2009; Hruschka et al. 2005). In this study, we investigated salivary cortisol and DHEA in a population of children residing in a rural community on the island of Dominica. Our aims were: 1) to describe diurnal fluctuations and day-to-day stability and changes in the salivary concentrations of the two adrenal steroids under basal conditions, 2) to investigate cortisol and DHEA responses to a mild psychosocial stressor, i.e., a structured interview to collect sociometric data; and 3) to describe age-related changes in salivary cortisol and DHEA using a cross-sectional approach.

\section{Methods}

The protocol used in this study was approved by the Institutional Review Board of the University of Missouri.

\section{Subjects and Saliva Collection}

Study subjects were 59 children (27 girls and 32 boys, mean age 7.83) living with their families in the village of Bwa Mawego, on a mountainous coastal region of Dominica. Approximately 500 residents live in households clumped in 5 neighborhoods. Until 2009 only one main road was paved, therefore each household could be reached only walking through rough, hilly tracks. Saliva samples were collected from children by research assistants, who walked set routes from house to house (Flinn and England 1995). Children provided saliva samples three times a day on four days during the 
summers of 2008 and 2009, while they were on summer school break. During July 2008, saliva samples were collected once in the early morning (6:00 am-9:00 am), once in the late morning-early afternoon (10:00 am-1:00 pm), and once in mid-afternoon (2:00 pm-5:00 pm). During August 2009, saliva samples were collected once in the early morning (8:00 am-10:00 am), once in the late morning (10:00 am-12:00 pm), and once in the early afternoon (12:00 pm-2:00 pm). Information regarding children's wake up times was obtained from their relatives (usually a parent or an older sibling). Saliva was collected by passive drooling through a straw into a polypropylene tube after stimulation of saliva with spearmint gum.

For a subset of children $(n=44)$ saliva samples were also collected in association to a mild psychosocial stressor, i.e., a videotaped standard interview used to gather information about the children's peer social networks. The interviews took place in the children's homes during the summer of 2009. During the interview, children were asked to identify other children with whom they spent time and played and to rate their best friends and least-liked children on several social measures (Benenson 1990; Cairns et al. 1995). Interviews lasted, on average, $20 \mathrm{~min}$, ranging from 10 to $36 \mathrm{~min}$. Relatives (e.g., siblings, mothers) were always in the house during the interview and were often present in the same room as the children. Three samples of saliva were collected: before the interview, right at the end of the interview, and $15 \mathrm{~min}$ afterward. The interviews were conducted in the afternoon between 2 and $6 \mathrm{pm}$ for all but four children that were interviewed in the morning.

Salivary hormone concentrations were measured using an enzymatic immune assay (Salimetrics LLC) at the Evolutionary Physiology and Ecology Laboratory of Indiana University. Intra-assay coefficients of variation (CV) were less than $5 \%$ for cortisol and less than $8 \%$ for DHEA. Inter-assay CV was $16.4 \%$ for cortisol and less than $10 \%$ for DHEA.

\section{Statistical Analysis}

Descriptive information about the study subjects is reported in Table 1. To test if missing values resulting from samples containing hormones below the detection limit were dependent on sex and age of the child we run logistic regression analyses for repeated measure using proc GENMOD (SAS 9.3) (Table 2). Growth models with three levels in which samples were nested within day and days were nested within subject (Hruschka et al. 2005; Singer 1998) were used to investigate the effects of time of collection relative to time since wake-up and several predictors of cortisol and DHEA. First, an unconditional means model was tested. This model is used to determine if significant variation exists at each level to warrant further analysis (Singer and Willett 2003). A conditional growth model was then tested, which helped to partition the variation between and within days and individuals in rate of change. In this model, time since wake-up (in hours) was entered as a level 1 parameter. Time since wake-up was centered at its grand mean, $5.6 \mathrm{~h}$ post-waking. The relative amount of within- versus between-individual variation was evaluated by means of the intraclass correlation coefficient (ICC) using the formulas in Hruschka et al. (2005). The ICC measures the reliability of repeated samples from the same individual. Restricted maximum-likelihood estimation (REML) was used to test significant random effects. 
Table 1 Descriptive statistics

\begin{tabular}{|c|c|c|c|c|c|c|}
\hline & \multicolumn{2}{|l|}{2008} & \multicolumn{2}{|l|}{2009} & \multicolumn{2}{|l|}{ interview } \\
\hline & Males & Females & Males & Females & Males & Females \\
\hline $\mathrm{N}$ & 28 & 24 & 25 & 18 & 23 & 21 \\
\hline \multirow[t]{2}{*}{ Age } & $7.64(5-11)$ & $7.95(5-11)$ & $7.91(5-11)$ & $7.89(5-10)$ & $7.86(5-11)$ & $7.95(5-10)$ \\
\hline & \multicolumn{2}{|l|}{2008} & \multicolumn{2}{|l|}{2009} & \multicolumn{2}{|l|}{ Interview } \\
\hline $\begin{array}{l}\text { Samples } \\
\text { x child }\end{array}$ & \multicolumn{2}{|l|}{$5.19 \pm 0.13$} & \multicolumn{2}{|l|}{$4.18 \pm 0.24$} & \multicolumn{2}{|l|}{3} \\
\hline \multirow{2}{*}{$\begin{array}{l}\text { Wake-up } \\
\text { time }\end{array}$} & Day 1 & $6: 44$ am $(4: 00-9: 20 \mathrm{am})$ & \multicolumn{2}{|c|}{$6: 52$ am $(5: 00-10: 00 \mathrm{am})$} & \multirow{2}{*}{\multicolumn{2}{|c|}{$6: 56$ am $(5: 00-8: 36 \mathrm{am})$}} \\
\hline & Day 2 & $6: 37$ am $(5: 00-8: 45 \mathrm{am})$ & \multicolumn{2}{|c|}{$5: 44$ am $(5: 45-9: 10 \mathrm{am})$} & & \\
\hline
\end{tabular}

There were 21 boys and 15 girls that provided samples during both years for a total 36 children representing $60 \%$ of the entire population sample. Across the two years there were 28 children that provided samples within 30 min since waking up, representing $4 \%$ of the entire salivary sample. Ages and wake-up times are given as mean and min-max range (in parenthesis)

Models were built by adding each hypothesized parameter one at a time. We first controlled for the effect of time of day, then we added age (a person level predictor) followed by sex (a person level predictor) to test developmental and sex effects. To determine if the interview elicited physiological responses we followed two approaches. First, we analyzed if there were differences between the three samples collected during the interview by means of a repeated analyses using a covariance pattern model (CPM)(Fitzmaurice et al. 2004). This method required the elimination of the 4 children who provided saliva during early morning resulting in a total of 40 children analyzed. In the second approach we added a day level dummy variable to the growth models. This dummy variable was coded as 0 if the sample was collected during a regular day and 1 if the sample was collected during the day of the interview. To test which model fitted better between the growth models, nested models were compared using the Maximum Likelihood (ML) deviance tests, which simultaneously tests for fixed and random effects (Singer and Willett 2003). This approach requires the subtraction of the -2 Log likelihood ( $-2 \mathrm{LL}$ ) between two competing models. The deviance is distributed as a $\chi^{2}$ with degrees of freedom $(d f)$ equal to the difference in parameters between the two models. In order to normally distribute the values, cortisol and DHEA concentrations were expressed in nmol/l and log-transformed.

Table 2 Number of samples below the detection limits of the assay

\begin{tabular}{lll}
\hline Hormone & Below Detection Limit & Log-likelihood (SE) \\
\hline Cortisol & $6 / 591(1 \%)$ & \\
DHEA & $119 / 591(20 \%)$ & \\
Age & & $-0.22( \pm 0.07)^{*}$ \\
Sex (Boy) & & $0.42( \pm 0.22)^{\dagger}$ \\
\hline
\end{tabular}

The probability that a sample is below the detection limits for DHEA as a consequence of the child age or sex are reported as log-likelihood based on repeated multiple logistic regression analysis. ${ }^{*} p<0.05, \dagger p<0.10$ 


\section{Results}

\section{Cortisol}

Cortisol decreased significantly throughout the day (Table 3; Fig. 1). Age and sex were not significant predictors of cortisol change and therefore were dropped from subsequent analyses (Table 3). The growth model analysis revealed that samples collected during the day of the interview had higher concentrations of cortisol relative to noninterview days $(010=-0.85, p<0.01$; Fig. 2). However, analyses of the three samples collected during and shortly after the interview failed to show statistical increases of cortisol $\left(\mathrm{F}_{2,75}=0.10 ; p=0.90\right.$; Fig. 3$)$. Within-day reliability of cortisol samples conditional to time since wake-up and interview was $\mathrm{ICC}=0.27$. Between-day reliability, representing the correlation between all samples from the same subject, was $\mathrm{ICC}=0.14$.

\section{DHEA}

DHEA did not significantly change through the day (Fig. 1), therefore time of day was dropped from subsequent analyses. The best model explaining DHEA variation showed significant effects of age (hormone concentrations were lower in younger than in older children) and cortisol (Table 4, model 7). This result is corroborated by the fact that the likelihood of finding a sample below the detection limit of the assay was higher in younger children (Table 2). Intermediate models testing for a quadratic effect of age (as it would be expected in case of adrenarche) and sex were not significant.

In the model testing the effect of interview, DHEA was higher during interview days compared to days in which there was no interview, but this effect disappeared when cortisol was added to the model. DHEA increased in a linear fashion throughout childhood $\left({ }_{001}=0.14, p<0.01\right)$ and there was a significant positive correlation between DHEA and cortisol levels $\left({ }_{003}=0.16, p<0.01\right)$. To make the ICCs for DHEA and cortisol comparable, we calculated the ICC for DHEA in the same way as we did for cortisol, controlling for time since wake up and interview. Within-day reliability of DHEA was $\mathrm{ICC}=0.35$ while between-days reliability was $\mathrm{ICC}=0.14$.

\section{Discussion}

Our study provides new information about salivary concentrations of cortisol and DHEA, both under baseline conditions and in response to mild stress, among children living in a rural village in Dominica. Although our sampling methodology prevented us from measuring the cortisol awakening response, we were able to demonstrate the typical cortisol diurnal cycle, in which concentrations were higher in the morning and lower in late afternoon. Unlike cortisol, DHEA did not exhibit significant variation in relation to time of the day. Since previous studies reported a DHEA circadian rhythm similar to that of cortisol in children, adolescents, and adults (Hucklebridge et al. 2005; Matchock et al. 2007), it is possible that our negative finding reflects our inability to systematically collect saliva samples upon awakening (only a few children in our study provided saliva samples within $30 \mathrm{~min}$ of waking up). 
Table 3 Model comparisons for Cortisol

\begin{tabular}{|c|c|c|c|c|c|}
\hline Parameters & Model 1 & Model 2 & Model 3 & Model 4 & Model 5 \\
\hline Intercept & $0.38(0.05)$ & $0.38(0.50) * *$ & $0.38(0.50) * *$ & $0.31(0.07)^{* *}$ & $1.07(0.10)^{* *}$ \\
\hline Time since waking & & $-0.11(0.01)^{* *}$ & $-0.11(0.01)^{* *}$ & $-0.11(0.01)^{* *}$ & $-0.14(0.01)^{* *}$ \\
\hline Age - & & & $-0.04(0.02) \dagger$ & - & - \\
\hline Sex (Female) & & & & $0.16(0.10)$ & - \\
\hline Interview $(0)$ & & & & & $-0.85(0.10)^{* *}$ \\
\hline \multicolumn{6}{|c|}{ Random effects (variance components) } \\
\hline \multicolumn{6}{|l|}{ Level 1} \\
\hline Residual & $0.68(0.05)^{* *}$ & $0.50(0.03)^{* *}$ & $\begin{array}{l}0.50(0.03)^{* *} \\
0.50(0.03)^{* *}\end{array}$ & $0.51(0.03)^{* *}$ & $0.50(0.03)^{* *}$ \\
\hline \multicolumn{6}{|l|}{ Level 2} \\
\hline Var Intercept & $0.07(0.04) \dagger$ & $0.20(0.05)^{*}$ & $0.21(0.05)^{* *}$ & $0.20(0.05)^{* *}$ & $0.09(0.03)^{* *}$ \\
\hline \multicolumn{6}{|l|}{ Level 3} \\
\hline Var Intercept & $0.11(0.04)^{*}$ & $0.05(0.04) \dagger$ & $0.03(0.03)$ & $0.04(0.03) \dagger$ & $0.09(0.03)^{* *}$ \\
\hline \multicolumn{6}{|l|}{ Model fit } \\
\hline $\begin{array}{l}-2 \text { log-likelihood } \\
\quad(-2 \mathrm{LL})\end{array}$ & $1,540.7$ & $1,448.4$ & $1,445.7$ & $1,446.1$ & $1,388.3$ \\
\hline
\end{tabular}

Estimates are based on $\log$ transformed values. Model 5 was chosen based on the deviance test, based on a $\chi^{2}$ distribution with $d f$ equal to the difference in parameters between the two model compared. Time since waking and age were centered to their grand mean. The number of observation was the same for every model and was equal to 585 . $\dagger p<0.10 ; * p<0.05, * * p<0.01$

Cortisol concentrations measured within the same day were weakly correlated though more highly correlated than cortisol concentrations measured on different days. These results are similar to those obtained by Hruschka et al. (2005) in Mongolian children. Salivary DHEA showed a slightly higher stability within days when compared to cortisol. Although Hucklebridge et al. (2005) showed that salivary DHEA levels from the same individual are highly correlated within and between days, they used a population of adults and therefore their results may not be directly comparable to ours.
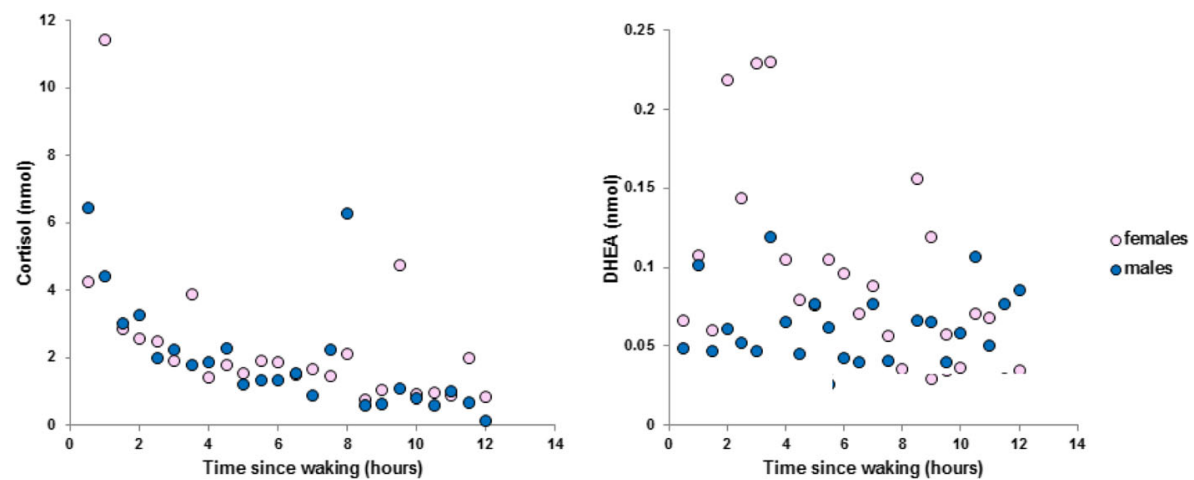

Fig. 1 Daily cortisol and DHEA distribution in the population of children from Bwa Mawego, rural Dominica. Dots represent cortisol and DHEA mean values on a 30 min intervals 


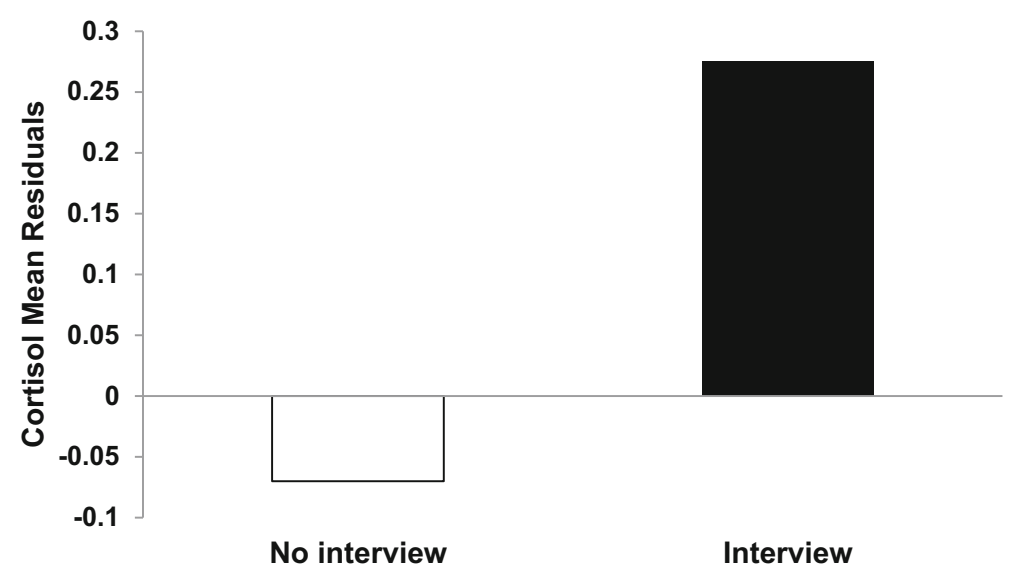

Fig. 2 Mean residuals for cortisol based on the multilevel model. Residuals are significantly higher during the day of the interview $(b=-0.85 ; \mathrm{SE}=0.10 ; p<0.001)$

We found that cortisol was positively associated with DHEA output once age was controlled for. This association may be due to joint regulation of the two hormones by ACTH or to correlations between the two hormones and anthropometric characteristics such as body weight and nutrition (Remer and Manz 1999). DHEA showed a stronger association with children's age than cortisol, DHEA levels being higher in older children. These results are consistent with those of previous research showing that basal plasma and salivary cortisol levels change only slightly throughout childhood and adolescence, whereas DHEA secretion shows a stronger increase with age (Ducharme et al. 1976; de Peretti and Forest 1976; Parker et al. 1983). In our study, however, we did not detect the sharp increase in DHEA levels that has been reported to occur in conjunction with adrenarche (Hopper and Yen 1975). Furthermore, although some studies have reported a sex difference in the timing of the increase in DHEA relative to adrenarche, or in overall DHEA concentrations (Ducharme et al. 1976; de Peretti and

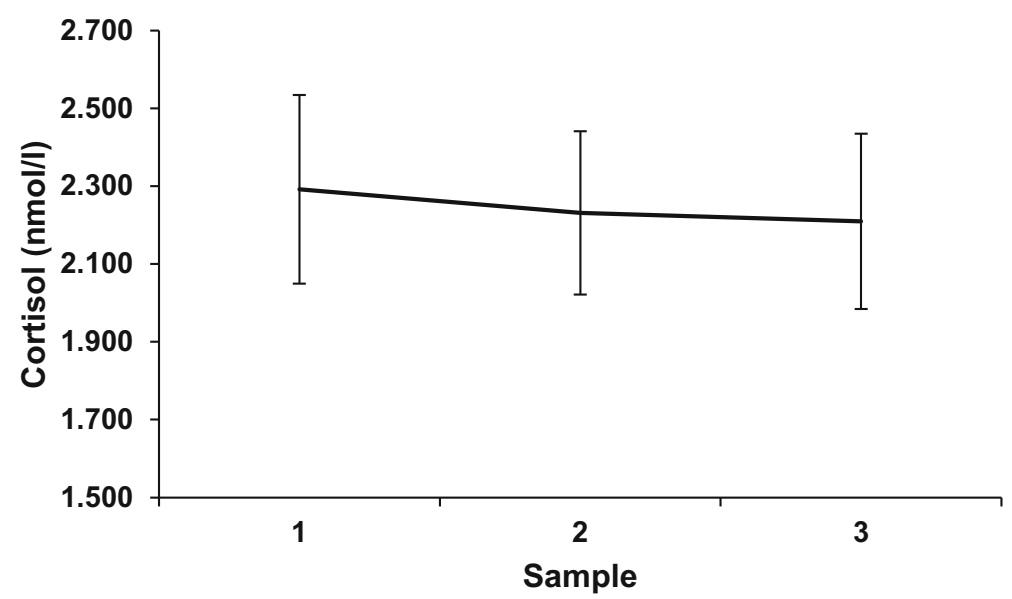

Fig. 3 Cortisol concentration of the three samples collected during the videotaped sociometric interview. The covariance pattern model for repeated measure showed no significant differences between sampling times. In average, the baseline sample was collected $8 \mathrm{~h}$ post waking 


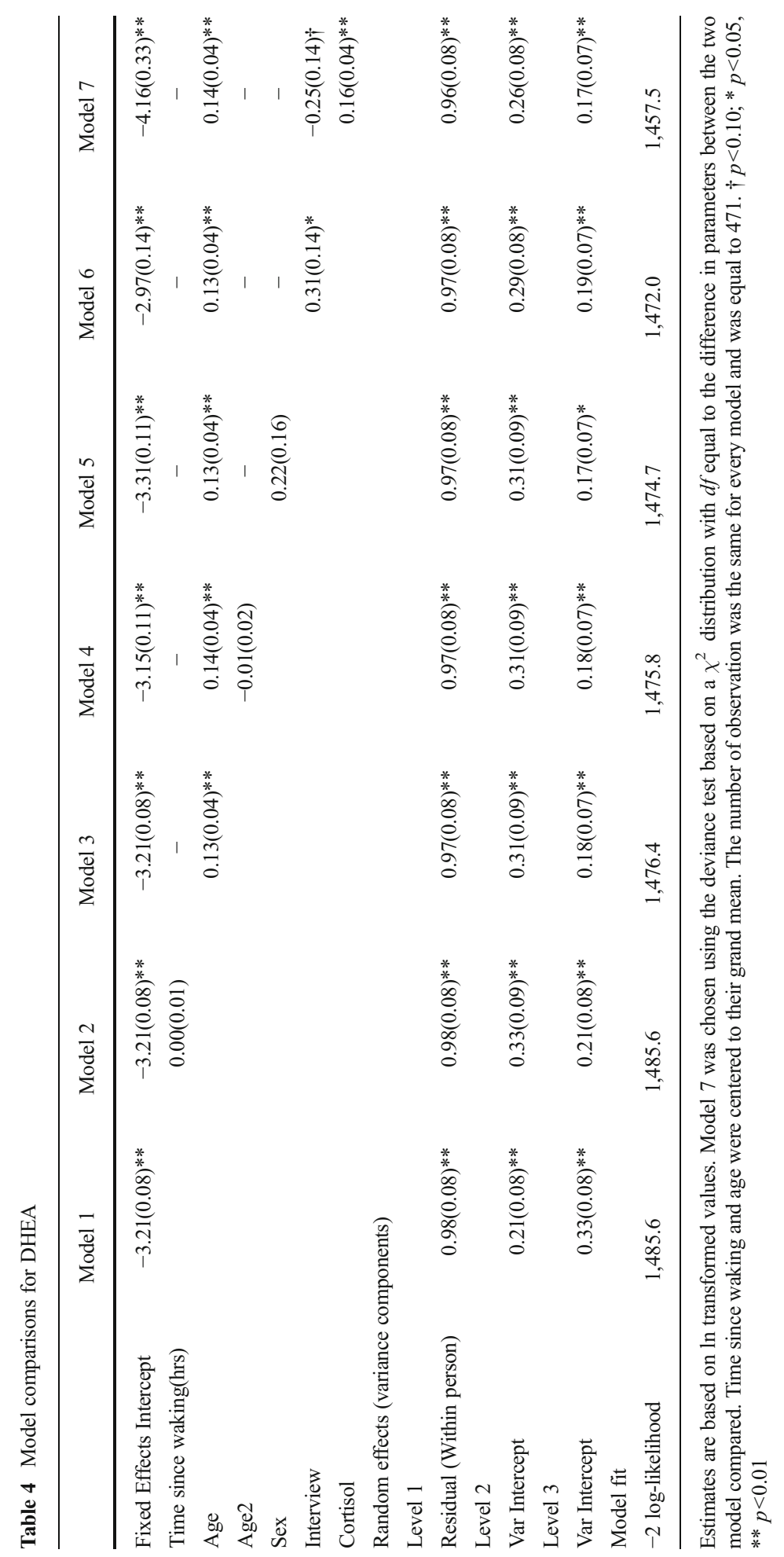


Forest 1976; Hopper and Yen 1975), we did not find significant sex differences in salivary DHEA in the children from this population. However, the likelihood of measuring samples with DHEA below the detection limit of the assay was higher when the samples were collected from boys, suggesting that some boys may indeed have had lower DHEA than girls.

Salivary cortisol concentrations were significantly higher on the day children were interviewed than on non-interview days. Being videotaped during an interview was a relatively novel procedure for the children in this study and may have been perceived as stressful. It is also possible that the children were uncomfortable discussing peer relationships in the presence of their relatives. However, there was no significant increase in cortisol in the sample collected shortly after the interview when compared to the pre-interview sample. Therefore, it is possible that the high cortisol on interview day reflected heightened arousal in the anticipation of the interview rather than a response to the interview itself. Either way, our results are consistent with those obtained in previous studies of this population in showing that children's HPA axis is extremely sensitive to social events and changes occurring in their daily lives (Flinn and England 1995, 2003; Flinn 2009) and a similar anticipatory effect of social challenges on cortisol levels has also been reported for North American children and adolescents (Klimes-Dougan et al. 2001; Hastings et al. 2011). Similar to cortisol, DHEA was higher during interview days compared to days in which there was no interview. This effect may be the result of the correlation between DHEA and cortisol and it may suggest a direct mediating effect of cortisol (Topor et al. 2011) or an indirect mediating effect of ACTH. But based on our data, we conclude that our study provides no evidence that DHEA is as sensitive to mildly stressful, or arousing, events as cortisol is; the observed DHEA secretion in the anticipation of a mildly stressful event may be secondary to cortisol secretion.

Consistent with the data from previous studies of children from this population (Flinn and England 1995; Flinn 2009), the salivary cortisol levels measured in this study appear to be within the norm of western industrialized societies. Although the generalizability of our findings is limited by the relative small sample size of our study, our results can be the basis for future work investigating the maturation of the HPA axis during childhood and its sensitivity to the social environment in subject populations living in rural communities.

Acknowledgments We like to thank all the people of Bwa Mawego that kindly helped us in the study. Especially we would like to thank Eugenia Durand for her patience and her contagious cheerfulness in helping us collecting the data. We are very grateful to Tomas Cabeza de Baca for helping with sample collection on the field.

\section{References}

Adam, E. K. (2006). Transactions among adolescent trait and state emotion and diurnal and momentary cortisol activity in naturalistic settings. Psychoneuroendocrinology, 31, 664-679.

Auchus, R. J., \& Rainey, W. E. (2004). Adrenarche - physiology, biochemistry and human disease. Clinical Endocrinology, 60, 288-296.

Benenson, J. F. (1990). Gender differences in social networks. Journal of Early Adolescence, 10, 472-495. 
Cairns, R. B., Leun, M., Buchanan, L., \& Cairns, B. D. (1995). Friendship and social network in childhood and adolescence: fluidity, reliability and interrelations. Child Development, 66(5), 1330-1345.

Campbell, B. (2006). Adrenarche and the evolution of human life history. American Journal of Human Biology, 18, 569-589.

Conley, A. J., \& Bird, I. M. (1997). The role of cytochrome P450 17 alpha-hydroxylase and 3 betahydroxysteroid dehydrogenase in the integration of gonadal and adrenal steroidogenesis via the delta 5 and delta 4 pathways of steroidogenesis in mammals. Biology of Reproduction, 56, 789-799.

Corpechot, C., Robel, P., Axelson, M., Sjovall, J., \& Baulieu, E. E. (1981). Characterization and measurement of dehydroepiandrosterone sulfate in rat brain. Proceedings of the National Academy of Sciences USA, 78, $4704-4707$.

de Peretti, E., \& Forest, M. G. (1976). Unconjugated dehydroepiandrosterone plasma levels in normal subjects from birth to adolescence in human: the use of a sensitive radioimmunoassay. Journal of Clinical Endocrinology and Metabolism, 43, 982-991.

DeSantis, A. S., Adam, E. K., Doane, L. D., Mineka, S., Zinbarg, R. E., \& Craske, M. G. (2007). Racial/ethnic differences in cortisol diurnal rhythms in a community sample of adolescents. Journal of Adolescent Health, 41, 3-13.

Ducharme, J. R., Forest, M. G., De Peretti, E., Sempe, M., Collu, R., \& Bertrand, J. (1976). Plasma adrenal and gonadal sex steroids in human pubertal development. Journal Clinical Endocrinology and Metabolism, 42, 468-476.

Edwards, S., Hucklebridge, F., Clow, A., \& Evans, P. (2003). Components of the diurnal cortisol cycle in relation to upper respiratory symptoms and perceived stress. Psychosomatic Medicine, 65, 320-327.

Fitzmaurice, G. M., Laird, N. M., \& Ware, J. H. (2004). Applied longitudinal analysis. Wiley series in probability and statistics. Inc: John Wiley \& Sons.

Flinn, M. V. (2009). Are cortisol profiles a stable trait during child development? American Journal of Human Biology, 21, 769-771.

Flinn, M. V., \& England, B. G. (1995). Childhood stress and family environmnent. Current Anthropology, 36(5), 854-866.

Flinn, M. V., \& England, B. G. (2003). Childhood stress: endocrine and immune responses to psychosocial events. In J. M. Wilce (Ed.), Social \& Cultural Lives of Immune Systems (pp. 107-147). London: Routledge press.

Flinn, M. V., Nepomnaschy, P. A., Muehlenbein, M. P., \& Ponzi, D. (2011). Evolutionary functions of early social modulation of hypothalamic-pituitary-adrenal axis development in humans. Neuroscience Biobehavioral Reviews, 35, 1611-1629.

Fries, E., Hesse, J., Hellhammer, J., \& Hellhammer, D. H. (2005). A new view on hypocortisolism. Psychoneuroendocrinology, 30, 1010-1016.

Girgis, R., Abrams, S. A., Castracane, V. D., Gunn, S. K., Ellis, K. J., \& Copeland, K. C. (2000). Ethnic differences in androgens, IGF-I and body fat in healthy prepubertal girls. Journal of Pediatric Endocrinology and Metabolism, 13, 497-503.

Goodyer, I. M., Herbert, J., Altham, P. M., Pearson, J., Secher, S. M., \& Shiers, H. M. (1996). Adrenal secretion during major depression in 8 to 16 years old, I. Altered diurnal rythms in salivary cortisol and dehydroepiandrosterone (DHEA) at presentation. Psychological Medicine, 26, 245-256.

Granger, D. A., Schwartz, E. B., Booth, A., Curran, M., \& Zakaria, D. (1999). Assessing dehydroepiandrosterone in saliva: a simple radioimmunoassay for use in studies of children, adolescents and adults. Psychoneuroendocrinology, 24, 567-579.

Gunnar, M., \& Quevedo, K. (2007). The neurobiology of stress and development. Annual Reviews of Psychology, 58, 145-173.

Hastings, P. D., Ruttle, P. L., Serbin, L. A., Mills, R. S. L., Stack, D. M., \& Schwartzman, A. E. (2011). Adrenocortical responses to strangers in preschoolers: relations with parenting, temperament, and psychopathology. Developmental Psychopathology, 53(7), 694-710.

Havelock, J. C., Auchus, R. J., \& Rainey, W. E. (2004). The rise in adrenal androgen biosynthesis: adrenarche. Seminars in Reproductive Medicine, 22, 337-347.

Hopper, B. R., \& Yen, S. S. (1975). Circulating concentrations of dehydroepiandrosterone and dehydroepiandrosterone sulfate during puberty. Journal of Clinical Endocrinology and Metabolism, 40, 458-461.

Hruschka, D. J., Kohrt, B. A., \& Worthman, C. M. (2005). Estimating between- and within-individual variation in cortisol levels using multilevel models. Psychoneuroendocrinology, 30, 698-714.

Hucklebridge, F., Hussain, T., Evans, P., \& Clow, A. (2005). The diurnal patterns of the adrenal steroids cortisol and dehydroepiandrosterone (DHEA) in relation to awakening. Psychoneuroendocrinology, 30, 51-57.

Ibanez, L., Dimartino-Nardi, J., Potau, N., \& Saenger, P. (2000). Premature adrenarche-normal variant or forerunner of adult disease? Endocrine Reviews, 21, 671-696. 
Izawa, S., Sugaya, N., Shirotsuki, K., Yamada, K. C., Ogawa, N., Ouchi, Y., et al. (2008). Salivary dehydroepiandrosterone secretion in response to acute psychosocial stress and its correlations with biological and psychological changes. Biological Psychology, 79, 294-298.

Jankord, R., \& Herman, J. P. (2008). Limbic regulation of hypothalamo-pituitary-adrenocortical function during acute and chronic stress. Annals of the New York Academy of Sciences, 1148, 64-73.

Kajantie, E., \& Phillips, D. I. (2006). The effects of sex and hormonal status on the physiological response to acute psychosocial stress. Psychoneuroendocrinology, 31, 151-178.

Karishma, K. K., \& Herbert, J. (2002). Dehydroepiandrosterone (DHEA) stimulates neurogenesis in the hippocampus of the rat, promotes survival of newly formed neurons and prevents corticosterone-induced suppression. European Journal of Neuroscience, 16, 445-453.

Kimonides, V. G., Spillantini, M. G., Sofroniew, M. V., Fawcett, J. W., \& Herbert, J. (1999). Dehydroepiandrosterone antagonizes the neurotoxic effects of corticosterone and translocation of stressactivated protein kinase 3 in hippocampal primary cultures. Neuroscience, 89, 429-436.

Klimes-Dougan, B., Hastings, P. D., Granger, D. A., Usher, B. A., \& Zahn-waxlerb, C. (2001). Adrenocortical activity in at-risk and normally developing adolescents: Individual differences in salivary cortisol basal levels, diurnal variation, and responses to social challenges. Development and Psychopathology, 13, 695719.

Kudielka, B. M., \& Kirschbaum, C. (2005). Sex differences in HPA axis responses to stress: a review. Biological Psychology, 69(1), 113-132.

Labrie, F. (2004). Adrenal androgens and intracrinology. Seminars in Reproductive Medicine, 22, 299309.

Labsy, Z., Prieur, F., Le Panse, B., Do, M. C., Gagey, O., Lasne, F., et. al. (2013). The diurnal patterns of cortisol and dehydroepiandrosterone in relation to intense aerobic exercise in recreationally trained soccer player. Stress, 16(2), 261-265.

Lennartsson, A. K., Kushnir, M. M., Berqquist, J., \& Jonsdottir, I. H. (2012). DHEA and DHEA-S response to acute psychosocial stress in healthy men and women. Biological Psychology, 90(2), 143-149.

Majewska, M. D. (1995). Neuronal actions of dehydroepiandrosterone. Possible roles in brain development, aging, memory, and affect. Annals of the New York Academy of Sciences, 774, 111-120.

Marceau, K., Ruttle, P. L., Shirtcliff, E. A., Essex, M. J., \& Susman, E. J. (2014). Developmental and contextual considerations for adrenal and gonadal hormone functioning during adolescence: implications for adolescence mental health. Developmental Psychobiology. doi:10.1002/dev.21214.

Matchock, R. L., Dorn, L. D., \& Susman, E. J. (2007). Diurnal and seasonal cortisol, testosterone, and DHEA rhythms in boys and girls during puberty. Chronobiology International, 24, 969-990.

McEwen, B. S., \& Gianaros, P. J. (2010). Central role of the brain in stress and adaptation: links to socioeconomic status, health, and disease. Annals of the New York Academy of Sciences, 1186, 190-222.

Miller, G. E., Chen, E., \& Zhou, E. S. (2007). If it goes up, must it come down? chronic stress and the hypothalamic-pituitary-adrenocortical axis in humans. Psychology Bulletin, 133, 25-45.

Nguyen, A. D., \& Conley, A. J. (2008). Adrenal androgens in humans and nonhuman primates: production, zonation and regulation. Endocrine Development, 13, 33-54.

Nyberg, C. H. (2012). Diurnal cortisol rhythms in Tsimane' Amazonian foragers: new insights into ecological HPA axis research. Psychoneuroendocrinology, 37, 178-190.

Parker, L. N., Lifrak, E. T., \& Odell, W. D. (1983). A 60,000 molecular weight human pituitary glycopeptide stimulates adrenal androgen secretion. Endocrinology, 113, 2092-2096.

Pratt, J. H., Manatunga, A. K., Wagner, M. A., Jones, J. J., \& Meaney, F. J. (1990). Adrenal androgen excretion during adrenarche. Relation to race and blood pressure. Hypertension, 16, 462-467.

Price, D. A., Close, G. C., \& Fielding, B. A. (1983). Age of appearance of circadian rhythm in salivary cortisol values in infancy. Archives of Disease in Childhood, 58, $454-456$.

Remer, T., \& Manz, F. (1999). Role of nutritional status in the regulation of adrenarche. Journal of Clinical Endocrinology and Metabolism, 84, 3936-3944.

Rosenfeld, R. S., Hellman, L., Roffwarg, H., Weitzman, E. D., Fukushima, D. K., \& Gallagher, T. F. (1971). Dehydroisoandrosterone is secreted episodically and synchronously with cortisol by normal man. Journal of Clinical Endocrinology and Metabolism, 33, 87-92.

Shirtcliff, E., Zahn-Waxler, C., Klimes-Dougan, B., \& Slattery, M. (2007). Salivary dehydroepiandrosterone responsiveness to social challenge in adolescents with internalizing problems. Journal of Child Psychology and Psychiatry, 48(6), 580-591.

Singer, J. D. (1998). Using SAS proc mixed to fit multilevel models, hierarchical models, and individual growth models. Journal of Educational and Behavioral Statistics, 24(4), 323-355.

Singer, J. D., \& Willett, J. B. (2003). Applied longitudinal data analysis: modeling change and event occurrence. Press: Oxford Univ. 
Styne, D. M., \& Grumbach, M. M. (2008). Puberty: ontogeny, neuroendocrinology, physiology, and disorders. In K. Larsen \& P. Melmed (Eds.), Williams textbook of Endocrinology (pp. 969-1166). Philadephia: Saunders.

Sulcova, J., Hill, M., Hampl, R., \& Starka, L. (1997). Age and sex related differences in serum levels of unconjugated dehydroepiandrosterone and its sulphate in normal subjects. Journal of Endocrinology, 154(1), 57-62.

Topor, L. S., Asai, M., Dunn, J., \& Majzoub, J. A. (2011). Cortisol stimulates secretion of dehydroepiandrosterone in human adrenocortical cells through inhibition of 3betaHSD2. Journal of Clinical Endocrinology and Metabolism, 96, E31-39.

van Cauter, E., Leproult, R., \& Kupfer, D. J. (1996). Effects of gender and age on the levels and circadian rhythmicity of plasma cortisol. Journal of Clinical Endocrinology and Metabolism, 81, 2468-2473.

Weitzman, E. D., Fukushima, D., Nogeire, C., Roffwarg, H., Gallagher, T. F., \& Hellman, L. (1971). Twentyfour hour pattern of the episodic secretion of cortisol in normal subjects. Journal of Clinical Endocrinology and Metabolism, 33, 14-22. 